\title{
KERAGAMAN KELINCI LAUT (NUDIBRANCHIA) DI PERAIRAN LAUT SULAWESI UTARA
}

\author{
Diversity of marine Rabbit (Nudibranchia) in Marine Waters of North Sulawesi \\ Inri K. K. Mantiri ${ }^{1^{\star}}$, Rosita A. J. Lintang ${ }^{1}$, Farnis B. Boneka ${ }^{1}$, \\ Billy Th Wagey ${ }^{1}$, Adnan S. Wantasen ${ }^{2}$, and *Medy Ompi ${ }^{1}$
}

1. Program Studi IImu Kelautan, FPIK UNSRAT Manado.

2. Jurusan Manajemen Sumber Daya Perairan, FPIK UNSRAT Manado.

Email: ompimedy@unsrat.ac.id

\begin{abstract}
This study aims to 1) identify the species of Nudibranchia in North Sulawesi marine waters, especially in Malalayang waters, Teep waters, Sangihe waters, Bunaken waters, Gangga waters and Lembeh straits, 2) find out species of Nudibranchia that is found in all sites, and 3) find out index community structure of Nudibranchia in all sites. The result show that there were 11 species of Nudibranchia in Malalayang waters, 27 species in Lembeh Strait, 11 species in Teep waters, 57 species in Bunaken waters, 91 species in Bangka waters, and 20 species in Sangihe waters. Up to now, there were 139 species of Nudibranchia in North Sulawesi marine waters, where Species of Phyllidiella pustulosa, Phyllidia ocellata, Phyllidia varicose, Chromodoris annae, and Glossodoris cincta were found in all study locations. The species of Doriprismatica atromarginata was only found in the Malalayang waters. A high Index Diversity was found in Bunaken and Bangka waters, and a middle Index Diversity was found in the waters of Lembeh Strait, Teep, and Sangihe. A stable community structure was found for all locations, while a low domination was categorized to all locations.
\end{abstract}

Keywords: Nudibranchia, species, diversity, evenness, domination, and community structure.

\begin{abstract}
Abstrak
Penelitian ini bertujuan 1) mengidentifikasi jenis-jenis Nudibranchia di Perairan Sulawesi Utara, khususnya di Perairan Malalayang, Perairan Teep, Perairan Sangihe, Perairan Bunaken, Perairan Gangga dan Selat Lembeh, 2) mengetahui jenis-jenis yang ditemukan di semua lokasi, dan 3) mengetahui nilai indeks struktur komunitas Nudibranchia di keenam lokasi. Jenis Nudibranchia yang ditemukan di Perairan Malalayang ada 11 spesies, 27 jenis di Selat Lembehm 11 jenis di perairan Taep, 57 jenis di perairan Bunaken, 91 jenis di perairan Bangka, dan 20 jenis di perairan Sangihe. Ada 134 jenis Nudibranchia yang teridentidfikasi di perairan laut Sulawesi Utara, di mana jenis-jenis Phyllidiella pustulosa, Phyllidia ocellata, Phyllidia varicose, Chromodoris annae, dan Glossodoris cincta ditemukan di semua lokasi penelitian. Jenis Doriprismatica atromarginata ditemukan hanya di perairan Malalayang. Indeks keragaman dikategorikan tinggi di dua perairan, yaitu Bunaken dan perairan Gangga, dan Indeks Keragaman dengan kategori sedang teridentifikasi di Malalayang, Taep, Sangihe dan Selat Lembeh. Semua lokasi tergolong memiliki komunitas Nudibranchia yang stabil, di mana dominasi jenis tergolong rendah.
\end{abstract}

Kata kunci: Nudibranchia, spesies, keanekaragaman, kemerataan, dominasi, dan struktur komunitas.

\section{PENDAHULUAN}

Perairan Sulawesi Utara berada di salah satu posisi segitiga karang dengan keanekaragaman sumberdaya yang tinggi dibandingkan dengan perairan lainnya di dunia. Nudibranchia adalah satu group Phylum Moluska, Kelas Gastropoda yang berkontribusi bagi tingginya keragaman di perairan ini. Biota ini tinggal di dasar perairan, berukuran kecil, tidak memiliki cangkang pelindung, dikenal sebagai kelinci laut. Corak warna yang dimiliki menjadikan dasar perairan nampak warna warni yang telah menjadikan banyak penyelam, termasuk turis, sangat 
menikmati pemandangan bawah laut ini (Ompi et al, 2019). Ada jenis-jenis dari biota ini yang memiliki 'biosubstances' yang dapat diextract untuk kebutuhan sumber bahan baku bagi obat-obatan (Kaligis et al, 2018).

Nudibranchia memiliki bahan-bahan beracun yang disemprot keluar di saat terancam oleh kehadiran predator (Kaligis et al, 2016). Biota inipun dapat sebagai sumber makanan, yang berberan sebagai salah satu sumber energy bagi biota lainnya dalam suatu rantai makanan (Murniasih, 2005).

Gosliner et al (2008) mendata bahwa ada 2000 jenis Nudibranchia di perairan Indo-Pasific, di mana keragaman jenis dapat bervariasi menurut lokasi (Ompi et al 2019; Nani et al (2019, Kaligis et al, 2018). Kehadiran jenis-jenis Nudibranchia dapat ditententukan oleh beragam faktor, termasuk substrat, ketersediaan makanan, predator, dan faktor lingkungan lainnya (Ompi et al, 2019). Variasi jenis-jenis Nudibranchia di lingkungan dan lokasi yang berbeda adalah memungkinkan terjadi, yang menjadikan keragaman biota ini di suatu berairan dapat berbeda.

Tujuan dari penelitian adalah 1) untuk mengetahui jenis-jenis Nudibranchia di 6 lokasi periaran laut, yaitu Teep, Sangihe, Bunaken, Gangga, Malalayang, dan Selat lembeh; 2) mengidentifikasi jenis-jenis yang ditemukan di ke enam lokasi penelitian, serta 3) mengetahui keanekaragaman, keseragaman, dan dominansi jenis-jenis Nudibranchia di 6 perairan laut.

\section{METODE PENELITIAN}

\section{Tempat dan Waktu Penelitian}

Lokasi pengumpulan data adalah perairan pesisir Sulawesi Utara, lebih khusus perairan Malalayang Kota Manado, perairan Teep Kabupaten Minahasa Selatan, perairan Bunaken Kota Manado, Perairan Bangka Kabupaten Minahasa Utara, Perairan Sangihe Kabupaten Sangihe, dan Selat Lembeh Kota Bitung. Selanjutnya lokasi pengumpulan data ditampilkan pada Gambar 1.

\section{Teknik Pengambilan Data}

Pengambilan data Nudibranchia dilakukan dengan menggunakan data primer dan sekunder. Data primer, pengambilan data ini dengan menggunkaan 'roving diver visual survey method'. Metode ini, selain sesuai untuk biota-biota dasar dengan karakteristik kehadiran yang tidak menentu, juga digunakan untuk biota-biota yang hadir dalam jumlah yang sedikit (Sabdono et al, 2021). Pengambilan data primer di pesisir Malalayang dilakukan pada 11 Mei 2021. 


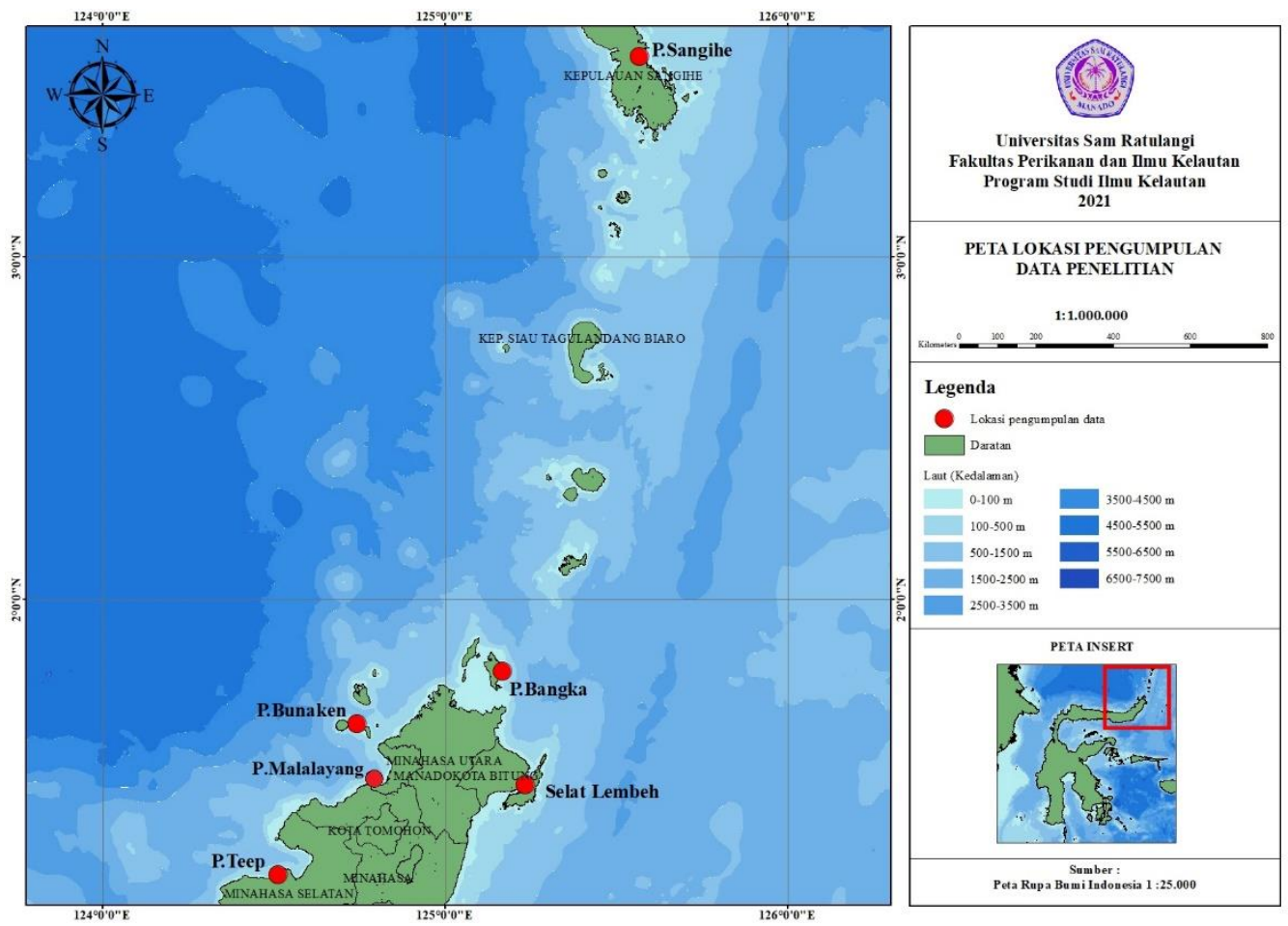

Gambar 1. Peta Lokasi Pengumpulan data Penelitian

Jenis-jenis Nudibranchia di ambil dengan bantuan diving dan snorkeling. Penyelam dengan bantuan alat-alat selam baik scuba, regulator, pemberat, masker fin yang berpasangan melakukan penyelaman sampai kedalam 18 meter selama 45 - 60 menit di dasar pearairan. Lima penyelam bersama-sama dalam observasi data, di mana 1 penyelam melakukan pemotretan, dan 4 penyelam lainnya secara berdekatan dan bersamaan melakukan pencarian biota. Penyelam yang melihat biota, memberi kode pada pemotret, untuk dilakukan pemotretan. Foto dilakukan fokus pada biota yang menempel pada substrat dasar dengan menggunakan Olimpus G 15.

Nudibranchia yang jenis belum diketahui, dipisahkan dari substrat, diangkat dengan menggunakan pingset, dimasukkan ke dalam kantong plastik berlabel, sebelum dibawah ke darat dan laboratorium Biologi Kelautan untuk diidentifikasi. Identifikasi dilakukan sampai tingkat genus dan jenis dengan menggunakan buku identifikasi, serta journal-journal yang telah dipublikasikan, seperti oleh Ompi dkk (2019); Ompi et al, 2019; Undap et al, 2019; Kaligis et al, 2018; Pungus et al 2017; Kaligis \& Ompi
2016; dan Gosliner et al., 2008). Jenisjenis Nudibranchia yang telah diidentifikasi, selanjutnya penerimaan nama-nama jenis dicek melalui bantuan 'The World Register of Marine Species (WoRMS)'.

Data sekunder, data ini diperoleh bukan dari pengalaman langsung, yaitu melalui publikasi-publikasi yang tersedia (Melfianora 2019). Sumber data sekundernya yakni berupa laporan ilmiah primer yang terdapat di dalam artikel atau jurnal (tercetak/noncetak), yang berkaitan dengan Nudibranchia di Sulawesi Utara antara lain (Undap et al 2019; Ompi dkk 2019; Ompi et al, 2019; Kaligis et al, 2018; Pungus et al 2017; dan Kaligis \& Ompi 2016).

\section{Analisis Data}

Analisa data Nudibranchia disesuaikan dengan 'roving diver visual survey method" baik untuk jenis-jenis, Indeks keanekaragaman $\left(\mathrm{H}^{\prime}\right)$, Indeks dominan, dan Indeks Keseragaman ('evenness index'), yang telah digunakan oleh Sulistiawati et al.,(2020), dan Subdono et al (2021). 


\section{Indeks Keanekaragaman (H')}

Dalam suatu struktur komunitas dapat diukur beberapa karakteristik, yaitu keanekaragaman, dominansi, termasuk kelimpahan. Keanekaragaman dapat ditentukan oleh banyaknya jenis, serta kemerataan kelimpahan individu tiap jenis yang didapatkan. Semakin besar nilai suatu

Tabel 1. Kategori Indeks Keanekaragaman $\left(\mathrm{H}^{\prime}\right)$

\begin{tabular}{|c|c|c|}
\hline No & Keanekaragaman & Kategori \\
\hline 1 & $\mathrm{H}^{\prime}<1$ & Rendah \\
\hline 2 & $1<\mathrm{H}^{\prime}<3$ & Sedang \\
\hline 3 & $\mathrm{H}^{\prime} \geq 3$ & Tinggi \\
\hline
\end{tabular}

Indeks keragaman $\left(\mathrm{H}^{\prime}\right)$ dihitung dengan menggunakan formula ShannonWiener (Krebs 1989) : adalah sebagai berikut:

$\mathrm{H}^{\prime}=-\sum_{i=1}^{S} \quad(\mathrm{Pi})\left(\log _{2} \mathrm{Pi}\right)$

Dimana $H^{\prime}=$ Indeks diversity (keanekaragaman) Shannon-Wiener, $\mathrm{Pi}=$ $\frac{n i}{N}$, ni $=$ jumlah individu masing-masing spesies, $\mathrm{N}=$ Total jumlah individu semua spesies. Indeks Keragaman rendah, jika $H^{\prime}=<1$, tinggi jika $H^{\prime}=\geq 3$, dan sedang jika $H^{\prime}=1<H^{\prime}<3$ (Tabel 1).

\section{Indeks Keseragaman (J)}

Indeks keseragaman (J) dihitung

Tabel 2. Kategori Indeks Keseragaman (J)

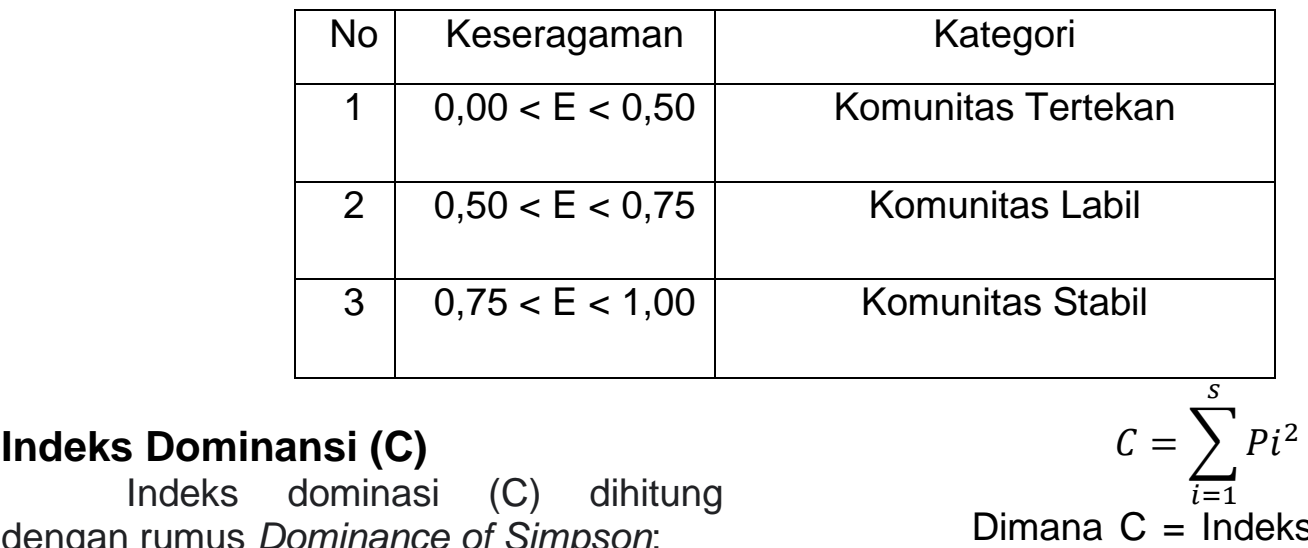

Indeks Dominansi (C)

Indeks dominasi (C) dihitung dengan rumus Dominance of Simpson: keanekaragaman berarti semakin banyak jenis yang didapatkan dan nilai ini sangat bergantung kepada nilai total dari individu masing-masing jenis atau genera. Keanekaragaman ( $\left.\mathrm{H}^{\prime}\right)$ mempunyai nilai terbesar jika semua individu berasal dari genus atau spesies yang berbeda-beda, sedangkan nilai terkecil jika semua individu berasal dari satu genus atau satu spesies saja. dengan menggukan rumus:

$$
J=\frac{H^{\prime}}{H^{\prime} \operatorname{maks}}
$$

Dimana, $\mathrm{J}=$ Indeks keseragaman jenis, $H^{\prime}=$ Indeks keanekragaman jenis (Shannon-Wiener function), nilai maksimum $\mathrm{H}^{\prime}=\log \mathrm{S}, \mathrm{S}=$ Jumlah spesies yang ditemukan (Krebs 1989). Indeks keseragaman range dari $0-1$, di mana komunitas yang tertekan dengan $\mathrm{J}=0,00$ $<\mathrm{J}<0,50$; Komunitas yang labil dengan $\mathrm{J}$ $=0,50<\mathrm{J}<0,75$, dan komunitas stabil dengan $\mathrm{J}=0,75<\mathrm{J}<1,00$ (Tabel 2). 
$=$ Proporsi individu pada setiap jenis $\mathrm{I}=1$, $0,50<\mathrm{C}<0,75 ;$ dan dominasi tinggi $2 \ldots$, n. Nilai Indeks Dominasi berada di dengan nilai $0,75<\mathrm{C}<1,00$ (Tabel 3). antara $0-1$, di mana dominasi rendah jika $\mathrm{C}=0,00<\mathrm{C}<0,50$; dominasi sedang jika

Tabel 3. Kategori Indeks Dominansi (C)

\begin{tabular}{|c|c|c|}
\hline No & Dominansi & Kategori \\
\hline 1 & $0,00<\mathrm{C}<0,50$ & Rendah \\
\hline 2 & $0,50<\mathrm{C}<0,75$ & Sedang \\
\hline 3 & $0.75<\mathrm{C}<1,00$ & Tinggi \\
\hline
\end{tabular}

\section{HASIL DAN PEMBAHASAN}

\section{Nudibranchia di Perairan Malalayang}

Jenis-jenis Nudibranchia yang ditemukan di perairan Malalayang, Sulawesi Utara terdiri dari 11 jenis (Tabel 4), di mana 9 jenis di antaranya ditampilkan pada Gambar 2. Kehadiran Nudibranchia di perairan Malalayang mengidentifikasi bahwa gastropoda yang tanpa memiliki cangkang pelindung masih hadir dan untuk pertama kali ditemukan di perairan ini.

Lokasi, lebih khusus habitat biota dasar di pasang surut ini, nampak telah berubah dari kondisi alamiah dengan adanya pembangunan tanggul-tanggul, jeti-jeti, bahkan penimbunan, serta aktivitas lainnya, yang dapat mempengaruhi habitat biota ini untuk tetap hadir dan menetap khususnya di perairan ini. Jenis-jenis Nudibranchia yang ditemukan di lokasi ini menempel pada karang hidup, karang mati, pecahan karang yang telah ditumbuh beragam alga.

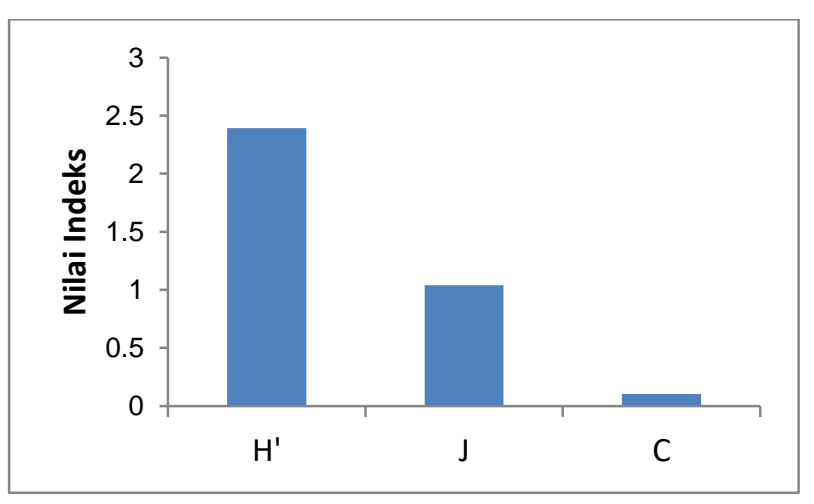

Gambar 3. Nilai Indeks Keragaman (H'), Indeks Keseragaman $(\mathrm{J})$, dan Indeks Dominasi $(\mathrm{C})$.
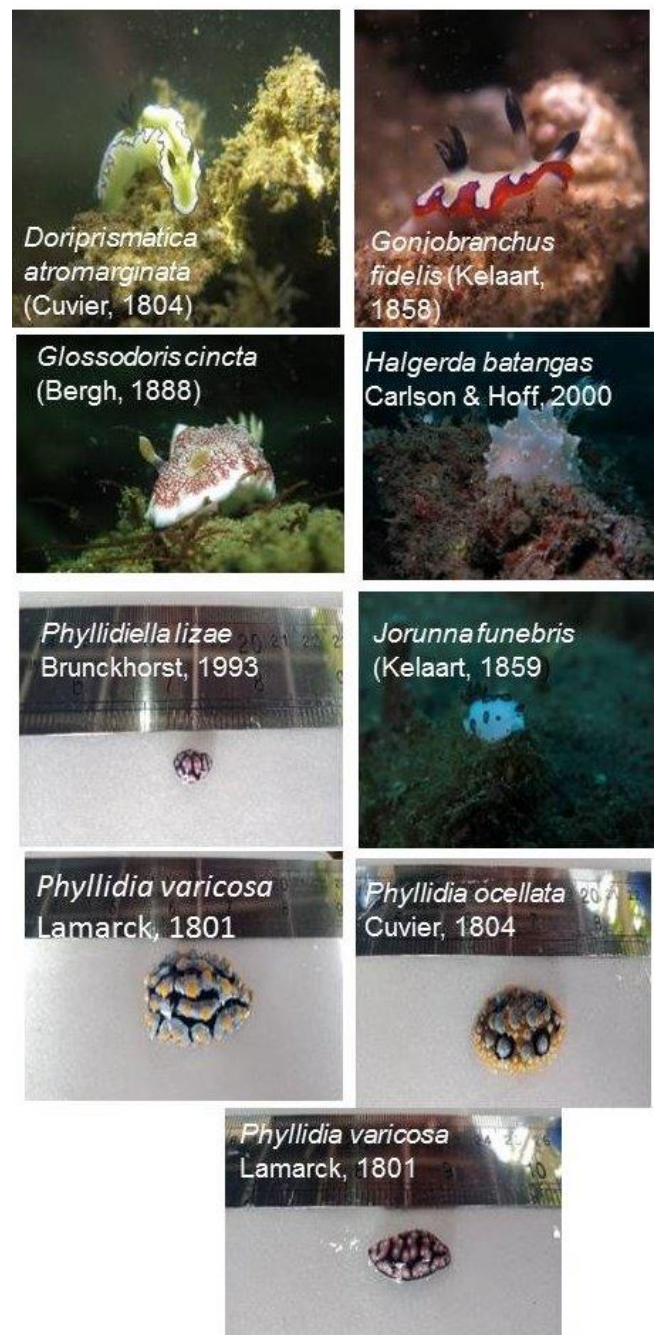

Gambar 2. Jenis-jenis Nudibranchia teridentifikasi di Perairan Malalayang 
Tabel 4. Jenis-jenis Nudibranchia di Perairan Malalayang

\begin{tabular}{|l|l|}
\hline No & \multicolumn{1}{|c|}{ Jenis } \\
\hline 1 & Chromodoris reticulata (Pease, 1866) \\
\hline 2 & Doriprismatica atromarginata (Cuvier, 1804) \\
\hline 3 & Glossodoris cincta (Bergh, 1888) \\
\hline 4 & Goniobranchus fidelis (Kelaart, 1858) \\
\hline 5 & Halgerda batangas Carlson \& Hoff, 2000 \\
\hline 6 & Jorunna funebris (Kelaart, 1859) \\
\hline 7 & Miamira sinuata (van Hasselt, 1824) \\
\hline 8 & Phyllidia ocellata Cuvier, 1804 \\
\hline 9 & Phyllidia varicosa Lamarck, 1801 \\
\hline 10 & Phyllidiella lizae Brunckhorst, 1993 \\
\hline 11 & Phyllidiella pustulosa (Cuvier, 1804) \\
\hline
\end{tabular}

Keragaman Nudibranchia di lokasi Malalayang tergolong sedang, yang didasarkan pada perhitungan Indeks Keragaman Shannon-Wiener diversity index $\left(\mathrm{H}^{\prime}\right)$ yang digunakan oleh Sabdono dkk (2021) dan Sulistiawati et al, (2020), dengan nilai 2.39 (Tabel 4). Nilai Indeks Keseragaman adalah 1.04, yang mengidikasi bahwa komunitas Nudibranchia di lokasi Malalayang adalah dalam kondisi stabil. Melalui perhitungan Indeks Dominasi, diperoleh nilai 0.1, mengidentifikasikan rendahnya dominansi dalam komunitas biota ini di perairan Malalayang.

\section{Nudibranchia di Perairan Lembeh, Teep, Bunaken, Bangka dan Sangihe}

Jenis Nudibranchia yang diidentifikasi untuk perairan Lembeh, Taep, Bunaken, Bangka, dan Sangihe memiliki jumlah jenis yang bervariasi, di mana Selat Lembeh dengan 27 jenis (Ompi dkk 2019), Taep dengan 11 jenis (Kaligis and Ompi 2016, Pungus dkk 2017), Bunaken dengan 57 jenis (Kaligis et al, 2018), Bangka dengan 91 jenis (Papu et al, 2020), dan Sangihe dengan 20 jenis (Undap et al, 2019).

$$
\text { Hasil perhitungan Indeks }
$$

Keanekaragaman $\quad\left(H^{\prime}\right), \quad$ Indeks Keseragaman (E), dan Indeks Dominasi (C) untuk 5 lokasi baik Selat Lembeh, Taep, Bunaken, Bangka, dan Sangihe (Tabel 5) adalah bervariasi.

Keragaman Nudibranchia nampak tinggi di perairan Bunaken dan Bangka, dengan $H^{\prime}=3.03$ untuk Bunaken, dan $H^{\prime}=3,92$ untuk Bangka (Tabel 5). Perairan dengan keragaman sedang teridentifikasi di 3 perairan, yaitu Selat Lembeh $(2,25)$ Taep $(2,30)$, dan Sangihe $(2,13)$.

Komunitas Nudibranchia di kelima perairan ada dalam kondisi stabil, yang teridentifikasi dari Indeks Keseragaman untuk Selat Lembeh adalah 0,97, Taep $(0,96)$, Bunaken $(0,75)$, Bangka $(0,87)$, dan Sangihe $(0,71)$ (Tabel 5). Dominansi untuk jenis Nudibranchia tergolong rendah dengan Indeks Dominansi untuk Lembeh adalah 0,11, Taep dengan 0,10, Bunaken dengan 0,08, Bangka dengan 0,03, dan Sangihe dengan 0,18 (Tabel 5).

Berdasarkan kalsifikasi ShannonWeiner (1949), keanekaragaman Nudibranchia di 2 perairan yaitu Bunaken dan Bangka nampak berada dalam kategori tinggi, dibandingkan dengan 3 perairan lainnya, termasuk dengan perairan Malalayang dengan kategori sedang, namun kondisi komunitas dalam kondisi stabil, dengan komptisi yang rendah. Keragaman sedang Nudibranchia di 4 perairan dapat disebabkan oleh aktivitas pembangunan di ke tiga perairan yang dapat menyebabkan gangguan terhadap aktivitas biota ini. 
Tabel 5. Indeks Keragaman ( $\left.H^{\prime}\right)$, Indeks Keseragaman $€$, dan Indeks Dominasi (C) untuk Selat Lembeh, Taep, Bunaken, Bangka, dan Sangihe,

\begin{tabular}{|l|l|l|l|l|l|l|}
\hline Lokasi & \multicolumn{1}{|c|}{$\mathrm{H}^{\prime}$} & Kategori & $\mathrm{E}$ & Kategori & $\mathrm{C}$ & Kategori \\
\hline Taep & 2,30 & Sedang & 0,96 & $\begin{array}{c}\text { Komunitas } \\
\text { Stabil }\end{array}$ & 0,10 & Rendah \\
\hline Lembeh & 2,25 & Sedang & 0,97 & $\begin{array}{c}\text { Komunitas } \\
\text { Stabil }\end{array}$ & 0,11 & Rendah \\
\hline Bunaken & 3,03 & Tinggi & 0,75 & $\begin{array}{c}\text { Komunitas } \\
\text { Stabil }\end{array}$ & 0,08 & Rendah \\
\hline Bangka & 3,92 & Tinggi & 0,87 & $\begin{array}{c}\text { Komunitas } \\
\text { Stabil }\end{array}$ & 0,03 & Rendah \\
\hline Sangihe & 2,13 & Sedang & 0,71 & $\begin{array}{c}\text { Komunitas } \\
\text { Labil }\end{array}$ & 0,18 & Rendah \\
\hline
\end{tabular}

Kondisi stress biota adalah salah satu akibat dari aktifitas-aktifitas manusia di atau sekitar perairan yang dapat menyebabkan biota terganggu. Sebagai contoh pembuatan jeti dan tanggul dengan mengintroduksi batu-batu serta sedimen di lokasi ini, menyebabkan perubahan profil pantai Malalayang, yang tentunya dapat berakibat pada perubahan habitat biota. Nudibranchia di perairan ini berada di dasar perairan $>5$ meter - 18 meter, di mana dampak aktivitas di pasang surut, termasuk introduksi tanah dan pasir dapat berakibat pada meningkatknya sedimen yang dapat menutupi bahkan mengganggu tempat hidup Nudibranchia di dasar perairan ini. Contoh lainnya, Selat lembeh dengan aktifitas industry di sepanjang daratan Selat lembeh, termasuk pelabuhan, dan tranportasi kapal yang masuk keluar selat, serta galangan kapal, dan aktifitas lainnya, dapat berakibat pada gangguan aktivitas biota Nudibranchia. Keragaman Nudibranchia di perairan ini tergolong rendah.

Namun demikian, keragaman Nudibranchia yang ada di perairan Sulawesi Utara, selain Bunaken dan Bangka, nampak tergolong lebih baik, dibandingkan dengan Nudibranchia yang berada di perairan lainnya di luar Sulawesi Utara, seperti perairan-perairan di pesisir Jepara, Pulau Jawa, dengan lokasi seperti Teluk Alur, Pulau Panjang, pesisir Bandengan dan Kartini, yang memiliki Indeks Keragaman yang rendah, dengan $H^{\prime}$ ada di bawah 1, aktivitas pembangunan dilaporkan telah berdampak pada meningkatnya stress bagi biota yang berakibat pada rendahnya keragaman Nudibranchia di perairan-perairan ini (Sabdono et al, 2021).

Rendahnya jumlah jenis adalah salah satu penyebab Indeks Keragaman Nudibranchia di perairan-perairan Jepara yang tergolong rendah, di mana dilaporkan teridentifikasi 6 jenis Nudibranchia di perairan-perairan ini (Sabdono et al, 2021). Jumlah jenis terendah, seperti di perairan Taep, yang memiliki 2 kali lipat jenis Nudibranchia, dibandingkan dengan Nudibranchia yang teridentifikasi di perairan Jepara.

Peraian Bunaken dan Bangka dibandingkan dengan ke empat perairan lainnya adalah dua perairan yang memiliki terumbu karang yang luas, yang sekaligus menjadi tempat tinggal yang cocok, baik mencari makanan, bertumbuh, bahkan reproduksi, bagi Nudibranchia. Luas terumbu karang di ke dua perairan dapat menggambarkan bervariasinya substrat yang dapat menjadi habitat bagi biota ini, seperti yang telah dilaporkan oleh Kaligis et al (2018); Ompi et al (2019), dan Papu et al (2020). Kedua perairan ini memiliki keanekaragaman Nudibranchia yang tergolong tinggi.

Jenis Phyllidiella pustulosa, Phyllidia ocellata, Phyllidia varicose, Chromodoris annae, dan Glossodoris cincta, teridentifikasi hampir terdapat disetiap perairan pengambilan data yang ada di Sulawesi Utara dapat disebabkan oleh kondisi lingkungan yang mendukung yang bagi jenis-jenis Nudibranchia ini, seperti 
kehadiran substrat karang mati yang menjadi tempat favorit untuk menempel bagi biota ini di setiap perairan di mana biota-biota ini hadir (Ompi et al 2019; Kaligis et al 2018). Ada 1 jenis, yaitu Doriprismatica atromarginata (Cuvier, 1804), yang teridentifikasi hanya di perairan Malalayang, atau tidak teridentifikasi di 5 perairan lainnya. Selain substrat, kondisi lingkungan perairan Malalayang dapat secara khusus menjadi tempat tinggal dari biota ini. Namun dalam penelitian, tidak adanya pengukuran terhadap kondisi lingkungan, seperti jenis-jenis substrat, salinitas, keasaman, bahkan kandungan oksigen perairan kondisi ini.

\section{KESIMPULAN}

Berdasarkan penelitian yang dilakukan dapat disimpulkan bahwa Jenis-jenis Nudibranchia yang teridentifikasi di perairan Sulawesi Utara adalah 139 jenis, di mana adanya jumlah jenis yang bervariasi untuk masing-masing perairan, baik Malalayang, Taep, Selat Lembeh, Bunaken, Bangka, dan Sangihe.

Indeks keanekaragaman

Nudibranchia dikategorikan sedang ada di perairan Malalayang $(2,39)$, Selat lembeh $(2,25)$, Taep $(2,30)$, dan Sangihe $(2,13)$. Indeks keragaman tinggi ada di peranan Bunaken (3,03) dan Bangka (3,92). Indeks Kesaragam tergolong stabil, di aman untuk Malalayang adalah 1, Selat lembeh 0,97, Taep 0,96, Bunaken 0,75, Bangka 0,87, dan Sangihe 0,71. Indeks dominansi (C) pada Selat lembeh adalah 0,11, Taep 0,10, Bunaken 0,08, Bangka 0,03 , Sangihe 0,18, dan Malalayang 0,1. Nilai indeks dominansi ini tergolong rendah untuk semua perairan.

Jenis Phyllidiella pustulosa, Phyllidia ocellata, Phyllidia varicose, Chromodoris annae, dan Glossodoris cincta, teridentifikasi hampir terdapat disetiap titik pengambilan data yang ada di Sulawesi Utara.

\section{DAFTAR PUSTAKA}

Dayrat, B. 2006. A Taxonomic Revision of Paradoris Sea Slugs (Mollusca: Gastropoda: Nudibranchia: Doridina). Zoological Journal of the Linnaean Society 147: 125-238

Gosliner TM, Behrens DW, Valdés A (2008) Indo-Pacific nudibranchsand sea slugs. A field guide to the world's most diverse fauna. Seachallengers natural history books, Gig Harbor, Washington, and California Academy of Sciences, San Francisco.

Krebs C. J. 1989. Ecological methodology. Haeper \& Row, Publisher. New York. 654 P.

Kaligis F. G. J., and Ompi M. 2016. Implementation of Environmentally Friendl Monitoring Method: "Green Watch" and "Image Analysis" in Sustainable Resource Utilization in the Coast Community of the Gulf of Amurang. Platax.

Kaligis F. G. J., Jan-Hendrik E., Dorothee Schillo, Jobel Dialao, Till F. Schaberle, Nils Böhringer,Robert Bara, Sven Reumschussel, Gabriele M. Konig and Heike Wagele. 2018. Second survey of heterobaranch sea slugs (Mollusca, Gastropoda, Heterobranchia) from Bunaken National Park, North Sulawesi, Indonesia - how much do we know after 12 years?. Marine Biodiversity Records 11:2. 20 hal.

Melfianora, 2019. Penulisan Karya Tulis IImiah Dengan Studi Literatur. UPT Balai pelatihan penyuluhan.

Murniasih, T. 2005. Substansi Kimia untuk Pertahanan Diri dari Hewan Laut Tak Bertulang Belakang. Oseana. Vol. XXX No. 2: 19 - 27. 
Ompi Medy, 2019. Nudibranchia (Gastropoda) di Perairan Tropis Selat Lembeh, Sulawesi Utara: Ketahui Sebelum Katastrofe. Manado. P.T Percikan Hati.

Ompi M., Lumoindong. F, Undap. N, Papu. Adelfia, \& Wagele. H. 2019. Monitoring Marine Heterobranchia in Lembeh Strait, North Sulawesi (Indonesia), in a changing environment. AACL Bioflux Vol 12, Issue 2.

Ompi Pricilia O. M., Farnis B. Boneka, Medy Ompi, Joice R. T. S. L. Rimper, Kaskasen A. Roeroe, dan Alex D. Kambey. 2019. Kelimpahan, Distribusi, dan Keragaman Nudibranchia di Nudifall dan Nudiretreat Selat Lembeh, Sulawesi Utara. Jurnal Pesisir dan Laut Tropis. Vol. 7 No. 2. Manado. 8 hal

Papu Adelfia, Nani Undap, Nancy A. M., Marco R. S., Ivan G. D., Rendy R. K., Marco Perin, Nathalie Yonow and Heike Wägele. 2020. First study on Marine Hetobranchia (Gastropoda, Mollusca) in Bangka Archipelago, North Sulawesi, Indonesia. Journal Diversity 12,52; doi:10.3390/d12020052

Pungus Faldy, Georis J. F. Kaligis dan Medy Ompi. 2017. Status Nudibranchia di Perairan Pantai Desa Teep Minahasa Selatan dan Selat Lembeh Bitung. Jurnal Pesisir dan Laut Tropis. Vol. 1 No. 2. Manado. 8 hal.

Sabdono Agus, Ocky K. R., Agus T., Mada T. S., Alexander M., and Rhesi K., 2021. An Ecological Assessment Of Nudibranch Diversity Among Habitats
Receiving Different Degrees Of Sedimentation In Jepara Coastal Waters, Indonesia. International Journal of Conservation Science. Vol 12, Issue 1.

Ian F. Spellerberg I. F., Peter J. F. 2003. A tribute to Claude Shannon (1916-2001) and a plea for more rigorous use of species richness, species diversity and the 'Shannon-Wiener' Index. Jounal of Macroekology: 12 (3): 177 179.

Sulistiawati Dwi, Kasim Mansyur, Aswad E. P., Novalina S., Aimudin L., Muhammad Nur A., Muhammad K., dan Wildanin P. S. H. 2020. Management Strategies Of Coral Reefs Fisheries In Bangga Laut Archipelago, Central Sulawesi, Indonesia. International Journal of Conservation Science. Palu. Vol. 11 Issue 4. 1083-1092.

Undap Nani, Adelfia Papu, Dorothee Schillo, Frans Gruber ljong, Fontje Kaligis, Meita Lepar, Cora Hertzer, Nils Böhringer, Gabriele M. König, Till F. Schäberle and Heike Wägele 2019. First Survey of Heterobranch Sea Slugs (Mollusca, Gastropoda) from the Island Sangihe, North Sulawesi, Indonesi. Journal Diversity. 11,170

WoRMS (World Register of Marine Species). 2020. Marine Species. http://www.marinespecies.org/. 